\title{
A contribution towards improving the applicability of the Myriophyllum aquaticum sediment contact test
}

\author{
Tanja Tomić ${ }^{*}\left(\mathbb{D}\right.$, Varja Mihajlović ${ }^{1}$, Tamara Jurca ${ }^{1}$, Aleksandra Tubić², Dejan Krčmar $^{2}$, Jelena Tričković ${ }^{2}$ \\ and Ivana Teodorović ${ }^{1}$
}

\begin{abstract}
Background: Whole sediment contact tests provide realistic exposure scenarios, but the inherent properties of sediments may play a significant role in organism's response and interfere with result interpretation. Recently, a sediment contact test with a rooted aquatic macrophyte Myriophyllum aquaticum has been standardized. The present study aims to distinguish between effects of basic sediment properties and sediment-bound pollutants on M. aquaticum growth and evaluate the method as a tool in sediment quality assessment. Tests with artificial sediments with different organic matter, sand and clay content, as well as freshwater sediments with different levels of contamination were conducted.
\end{abstract}

Results: Results were based on comparison to the standard artificial control sediment. Organic matter content and grain size distribution in different variants of artificial sediments significantly affected M. aquaticum growth. Growth was impaired in formulations with low (1\%) and high (10\%) organic matter content, while better growth of plants compared to control was recorded in artificial samples with higher fine particles content. Because of the presence of unmeasured pollutants in freshwater sediments and inherent sediment properties, results of the M. aquaticum sediment contact tests were not always in accordance with the results of chemical analysis. Whorl, shoot and root parameters had different variability and showed a particular growth pattern in natural sediments. If the threshold of $20 \%$ for sediment toxicity is applied, then about $60 \%$ of tested natural sediments may be considered as toxic. As sediment structure may influence plant growth, this interpretation may be false as the physico-chemical properties of the control sediment used for comparison are considerably different from the properties of natural sediments.

Conclusions: Since inherent properties showed a significant effect on plant growth, the use of suitable controls more similar to tested natural sediments is advisable. To avoid over-, but also under-estimations, the use of the strict toxicity threshold of $20 \%$ or even higher inhibition for this test can be recommended, provided the statistical power of the test is high. The results of this study might contribute to the ongoing process of including effect-based methods in water quality monitoring under the Water Framework Directive.

Keywords: Rooted aquatic plant, Whole sediment contact test, Freshwater sediment, Sediment quality

\section{Background}

The bioavailability, fate and distribution of chemicals in sediments are influenced by site-specific physical,

\footnotetext{
*Correspondence: tanja.tunic@dbe.uns.ac.rs

1 Department of Biology and Ecology, LECOTOX-Laboratory

for Ecotoxicology, Faculty of Sciences, University of Novi Sad, Trg Dositeja

Obradovića 2, 21000 Novi Sad, Serbia

Full list of author information is available at the end of the article
}

chemical and biological properties [1,2]. Even though the heterogeneity and dynamics of sediments raise the complexity of their analysis in risk assessment, ignoring them or their specific properties may lead to errors in assessing the ecotoxicological status of waters $[1,3]$.

Water Framework Directive (WFD) [4] aimed to achieve good ecological and chemical status of European waters by the year 2015-the goals which a number of 
EU member states failed to accomplish [5]. The WFD did not specifically deal with sediment and does not require EU member states to monitor sediment quality; however, sediment quality and good status of waters are closely related $[6,7]$. Based on the experiences of some member states, sediment quality could be a reason for not meeting the WFD objectives [8]. According to the WFD, good chemical status means complying with environmental quality standards (EQS) set at EU level for priority substances [9] amended by [10]. This directive lists priority substances and defines EQSs in biota and water, while member states can choose to monitor some of the priority substances, as well as nationally defined river basin specific pollutants in sediments, provided they are at least as protective as the ones from the EQS Directive [7].

Chemical analysis in sediment quality assessment, which was the predominant approach in the past few decades, was recognized as unrealistic, as chemicals present in sediments do not necessarily pose a risk to the resident biota, while the risk from unmeasured chemicals and mixture effects is overlooked [11]. In the 1980s, Long and Chapman suggested the Sediment Quality Triad (SQT) approach, which involved three lines of evidence: chemistry, sediment toxicity and benthic community structure [12]. The combination of different methodologies was supposed to provide a more holistic sediment quality evaluation. Today, toxicity tests are an integral part of sediment assessment as lines of evidence in the weight of evidence approach $[2,11,13,14]$. In addition to sediment pore water and elutriate tests, whole sediment contact tests can be useful tools in identifying effects of (bioavailable) sediment-bound chemicals and their mixtures providing more realistic exposure conditions $[15,16]$. Generally, assessment based on a single test is not favored and a battery of tests covering at least three species from different trophic levels and habitats is recommended [17]. It is widely accepted that the analysis of various functional groups provides more information on different exposure routes of substances with various modes of action [13], which gives the effect-based methods an important role in holistic environmental monitoring contributing to the EU strategy for a nontoxic environment $[17,18]$. Even though a lot of available effect-based methods such as batteries of in vitro and in vivo whole-organism bioassays require advancements, they are a link between ecological and chemical status of waters, and therefore may be valuable as routinely used tools in environmental monitoring and management of water bodies [18].

A number of protocols have been developed for sediment quality assessment: with microorganisms (e.g., [19]) and invertebrates (e.g., [20, 21]). Recently, a sediment contact test with a rooted aquatic macrophyte,
Myriophyllum aquaticum, was developed and standardized as a risk assessment tool [22]. The method can be applied in retrospective risk assessment, via whole sediment toxicity tests, as well as in prospective risk assessment via sediment spiking tests. Even though the method showed good practicability, reproducibility and was found to be a suitable tool to assess sediment toxicity [16], it is not routinely applied much. The M. aquaticum test is used as one of the optional tests in some European countries $([17,23]$ and Ute Feiler personal communication, November, 2018). The application of the $M$. aquaticum test is especially rare compared to the more frequently used whole sediment tests on invertebrates (e.g., [24]).

The inclusion of sediments in toxicity tests for benthic invertebrates and rooted aquatic plants not only raises the ecological realism in environmental risk assessment [25], but also increases the complexity in test result interpretation. In sediment quality assessment, particularly when using bioassays, general sediment properties rather than chemical contamination may play a key role $[13,15]$. The commonly used endpoint in plant toxicity testing is the inhibition of growth. The inherent properties of the tested sediments are often quite different from those of the artificial control sediment which might lead to false interpretations of the observed difference in the organism's response in samples. Since plant growth, reproduction and recovery from stress highly depend on nutrient concentration and availability, organic matter content, grain size and other properties, it is crucial to distinguish between the intrinsic variability of growth parameters, plant response to overall ecological conditions or various inherent sediment properties and the potential effect of sediment-bound toxicants. This also holds true for setting toxicity thresholds and development of Sediment Quality Guidelines (SQGs), as decision-making and management against Toxicity Thresholds and/or Probable Effect Level (TEL/PEL) values are still one of the most suitable approaches available and used in risk assessment and management [26-28].

Plant growth inhibition (I\%) based on relative growth rate of whorl fresh weight (RGR of wFW) in a sediment sample compared to control is the suggested test endpoint in the standard Myriophyllum aquaticum test [22]. We searched for potential M. aquaticum growth patterns in various formulations of the standard artificial control with different sand, clay and organic matter content, as well as in natural sediments with different levels of contamination. The response of the standard endpoint, as well as several additional growth parameters were compared to the corresponding test controls and the long-term laboratory control. The long-term laboratory control was derived from seven tests (seven 
average control values, each calculated from control replicates). The objectives were to (a) assess whether environmental factors such as sediment grain size and organic matter content in sediments significantly affect $M$. aquaticum growth in the standard laboratory test (b) differentiate between plant responses to inherent sediment properties and chemical stress caused by sediment-bound pollutants in natural sediments and accordingly to (c) evaluate the applicability of the standard test in natural sediment quality assessment.

\section{Methods}

\section{Sediment samples}

Artificial laboratory control sediments were prepared following the protocol [22] and contained $5 \%$ of organic matter-Sphagnum sp. dried peat, $74 \%$ of quartz sand, $20 \%$ kaolin clay and $1 \%$ of $\mathrm{CaCO}_{3}$. Five alternative artificial sediment formulations were tested (A1-A5), all differing from the standard control in peat, sand or clay content. The first two varied in peat and sand, while the other three varied in sand and clay content.

Natural sediments were taken from slow-flowing typical lowland rivers Tamiš (T6-14), Jegrička (J15) and Krivaja (K16), as well as from lake Ludaš (L17-19) (Danube River Basin, Vojvodina Province, Republic of Serbia; details of sampling sites are shown in Additional file 1: Text S1. Surface sediments $(0-10 \mathrm{~cm})$ were collected with a core sampler, homogenized and stored in glass jars in the dark at a temperature circa $4{ }^{\circ} \mathrm{C}$ until further use.

\section{Physical and chemical analyses}

Fractional analysis of sediment samples (particles $<2 \mu \mathrm{m}$, fraction in the range of $2-63 \mu \mathrm{m}$ and sand content) was carried out according to [29]. Contents of dry and organic matter were determined according to [30]. The analysis of sediments for metals, arsenic, organochlorine pesticides, polychlorinated biphenyls (PCBs) and polycyclic aromatic hydrocarbons (PAHs) was done according to EPA standard procedures described in Additional file 1: Text S2.

\section{Plant cultivation}

Myriophyllum aquaticum was cultivated on standard artificial sediment, watered to saturation and regularly irrigated with nutrient Steinberg solution at $25 \pm 2{ }^{\circ} \mathrm{C}$, illuminated with continuous cool white fluorescent lighting (85-135 $\mu \mathrm{E} / \mathrm{m}^{2} / \mathrm{s}$ equivalent to $\left.6500-10000 \mathrm{~lx}\right)$ [22]. The artificial sediment was checked for trace metals and the measured concentrations (expressed per $\mathrm{kg}$ of dry weight) were as follows: $\mathrm{Zn} 4.39 \mathrm{mg} / \mathrm{kg}$, $\mathrm{Cd}<0.15 \mu \mathrm{g} / \mathrm{kg}, \mathrm{Cu} 4.29 \mathrm{mg} / \mathrm{kg}$ and $\mathrm{Pb} 2.97 \mathrm{mg} / \mathrm{kg}$.

\section{Myriophyllum aquaticum sediment contact tests}

Seven Myriophyllum aquaticum sediment contact tests were run non-simultaneously according to protocol [22]: two tests of alternative formulations of artificial control sediments (A1-A5), three tests of Tamiš sediments (T6-T14), one test of samples from Jegrička and Krivaja (J15, K16) and one test of lake Ludaš samples (L17-19). At the start of the test, plants from $21 \pm 3$ days old pre-cultures were cut into whorls (fresh weight range $25 \pm 6 \mathrm{mg}$ ). Three whorls per replica, three replicates per each treatment and three-six per control (depending on a test), were planted into $80 \mathrm{~g}$ of test and control sediment per test vessel, at the premarked positions (1-3), closed with translucent lids with openings for aeration. The standard artificial sediment [22] was used as a control in all tests, tests were run in static conditions and exposure conditions were the same as during cultivation. During the exposure time of 10 days, plants were watered with nutrient solution and test vessels were randomized every $48-62 \mathrm{~h}$.

\section{Endpoints and growth parameters}

At the beginning of the test, the plant whorls from the laboratory culture were cut, their weight was measured (whorl fresh weight $(\mathrm{wFW})$ at day 0 ) and they were placed in test vessels. After the 10-day exposure, plant fresh weight was measured again ( $w F W$ at day 10$)$, and other growth parameters were also analyzed: shoot fresh weight $(\mathrm{sFW})$, total length of the shoots $(\mathrm{sL})$, root fresh weight $(\mathrm{rFW})$, total length of the roots (the sum of the roots) (rL). Root-shoot ratio, based on FW and $\mathrm{L}$ measurements was also calculated. Relative growth rates (RGRs) for each plant were calculated from the measured total plant fresh weights to enable calculation of the arithmetic mean of the RGR per test and control vessel according to protocol [22]. Inhibition (I\%) of relative growth rate was calculated for each sediment sample-treatment group, according to protocol. Percent inhibition of other growth responses were also calculated, but based only on measurements on day 10 . Equations are displayed in Additional file 1: Text S3.

\section{Data analysis}

Mean, standard deviation (SD) and coefficient of variation $(\mathrm{CV} \%)$ were calculated for specific growth rates and all other growth parameters. Results from control treatments of seven tests from this study (seven average test control values derived from corresponding test replicates) were collated and their average values was used as a long-term laboratory control (lc). Statistical differences between average test control values were determined with one-way ANOVA Fischer's method (at 0.05 significance 
level, Statistica v.13.3). Plant growth responses in test sediments were compared to corresponding test controls (tc), as well as the long-term laboratory control (lc) using Dunnett procedure, which integrates one-way ANOVA and $t$ test (or with Bonferoni's adjustment in case of nonequal number of replicates per treatment) as a post hoc test [31]. Significance was assigned uniformly at $p=0.05$. Statistical power of the test was assessed by minimum significant difference (MSD) between control and treatments for an observed parameter and sensitivity by the percentage of decrease compared to the corresponding control (MSD, \%). Since MSD (\%) is based on the inherent variability of a test parameter, it is automatically calculated during data analysis [31] and presented for each endpoint in all the tests conducted. Equation is displayed in Additional file 1: Text S3.

\section{Multivariate analysis}

Principal component analysis (PCA) was carried out with an Excel add-in (Addinsoft (2019), XLSTAT statistical and data analysis solution. Long Island, NY, USA. https ://www.xlstat.com). Results of the analysis were summarized by a correlation circle, observations chart and the correlation values table. Values that were not best represented in the first two dimensions were filtered out and not shown in the correlation circle. The Pearson correlation coefficients were calculated among all plant growth responses and other variables (organic matter, sand, fine particle content and concentrations of chemicals) with a significance level $=0.05$. Only chemicals measured in all samples were taken into account.

The multivariate linear regression analysis was performed using generalized linear models (GLMs) in $R$ software version 3.5.1 (R Development Core Team 2018). The GLMs were used to analyze the effect of sedimentrelated parameters such as organic matter, sand and fine particles content, as well as concentrations of relevant chemicals on the various plant growth responses. For each response variable, best model was chosen based on the corrected AIC values (AICc) [32] using the function stepAIC in R package MASS [33]. The evaluation of the model fit was performed by calculating the adjusted $\mathrm{R}$-squared values using the $r s q$ function from $\mathrm{R}$ package rsq [34].

\section{Results}

The inherent variability of the Myriophyllum aquaticum sediment contact test

The average values of $M$. aquaticum growth parameters of seven trials from this study are displayed in Table 1 and used as long-term laboratory control values. Average test control RGR was 0.105 (ranging from 0.094 to 0.127), while average variability based on RGR was $11.01 \%$ (ranging from 6.9 to $15.1 \%$, Additional file 1: Tables S1 and S3). Based on Fischer's analysis (at 0.05 significance level, Statistica v.13.3), differences were significant between controls in test 7 and all other test controls.

Apart from the low variability for average test control RGR, variability lower than $25 \%$ was recorded for average initial (wFW0) and final fresh whorl weight (wFW10), shoot fresh weight (sFW) and length (sL) (Table 1). Higher variability than $30 \%$ was recorded for root fresh weight $(\mathrm{rFW})$ and length ( $\mathrm{rL}$ ) and, consequently, for root-shoot ratios based on fresh weight and length measurements.

Average control values of 30 individual replicates for all growth parameters are displayed in Additional file 1: Table S1 showing a range of RGRs from 0.079 to 0.149 and their average value and CV\% 0.106 and $15.04 \%$, respectively.

The average variability $(\mathrm{CV} \%)$ in artificial and natural samples and minimum significant difference (MSD\%) of

Table 1 Long-term laboratory control values (mean-average values of growth parameters of seven tests; one test $=$ three-six control replicates; sd, standard deviation; CV\%, coefficient of variation)

\begin{tabular}{|c|c|c|c|c|c|}
\hline \multirow[t]{2}{*}{ Growth parameters } & \multicolumn{5}{|c|}{ Long-term laboratory control values (average of 7 tests) } \\
\hline & Mean & Range (min-max) & $\pm \mathrm{SD}$ & Median & CV\% \\
\hline wFW0_initial whorl fresh weight $(\mathrm{mg}), \mathrm{d} 0$ & 25.9 & $(24.2-28.4)$ & 1.9 & 25.7 & 7.2 \\
\hline wFW10_final whorl fresh weight (mg), d10 & 75.5 & $(66.3-94.1)$ & 10.1 & 73.5 & 13.3 \\
\hline RGR — relative growth rate based on wFW, (0-10 days) & 0.105 & $(0.094-0.127)$ & 0.01 & 0.103 & 11.01 \\
\hline sFW—shoot fresh weight (mg) & 28.6 & $(16.8-49.8)$ & 6.2 & 26.8 & 24.7 \\
\hline $\mathrm{sL}$-shoot length $(\mathrm{mm})$ & 25 & $(19.7-31.8)$ & 4.3 & 25.4 & 17.9 \\
\hline rFW_root fresh weight (mg) & 3.7 & $(1.4-8.1)$ & 1.1 & 3.7 & 34.2 \\
\hline $\mathrm{rL}$-root length (mm) & 55.8 & $(18.5-112.6)$ & 18.9 & 54.4 & 44 \\
\hline rFW/sFW—root-shoot ratio (fresh weight) & 0.16 & $(0.05-0.51)$ & 0.1 & 0.16 & 37.2 \\
\hline $\mathrm{rL} / \mathrm{sL}$-root-shoot ratio (length) & 2.35 & $(0.76-5.65)$ & 0.6 & 2.35 & 35.6 \\
\hline
\end{tabular}

Standard growth parameter according to ISO 16191 [22] 
7 tests for various growth parameters in tested sediments are displayed in Table 2 (CVs of tested samples and MSDs for individual tests are displayed in Additional file 1: Table S3).

Generally, the average variability of growth parameters in tested artificial and natural sediments showed a similar pattern as the variability in controls. Lower values of $\mathrm{CV} \%$ were recorded for $\mathrm{wFW}$ at d10, sL, RGR and $\mathrm{sFW}$ and higher for root growth parameters, while ranging considerably between treatments.

Highest statistical power or lowest MSD\% values were calculated based on wFW at d10, RGR, sL and sFW. Low sensitivity of tests based on root growth is a result of high root variability within treatments, including the control sediment and it is reflected in the fact that sometimes $50 \%$ and even $100 \%$ growth stimulations were not statistically significant (Additional file 1: Tables S2 and S3).

\section{The sediment contact tests Tests of artificial sediments with different $O M$, sand and clay content}

The structure of artificial sediments seemed to have quite an effect on M. aquaticum growth (Table 3, Fig. 1). Significantly lower RGR values were recorded in sediments A1 and A2 (with 1\% and 10\% of organic matter, respectively) compared to the standard control (with $5 \%$ of OM) (Table 3). Shoot growth was more affected than root growth. Even though these sediments did not contain hazardous substances, plant growth inhibition based on the standard endpoint was around $45 \%$ in both, with a $30.9 \%$ and $19.6 \%$ minimal statistical difference in tests compared to corresponding test and long-term control, respectively (Additional file 1 : Table $\mathrm{S} 3$ ).

Plants seemed to prefer artificial sediments with higher content of clay (A3, A4 and A5) than in the control sediment. Growth stimulation of RGR in all three artificial sediments compared to control was recorded. The best overall growth was recorded in sediment A3 (containing 47\% sand and $47 \%$ clay), regardless of the control used for comparison (test or long-term). Minimal statistical differences in these tests compared to test and long-term control were $17.9 \%$ and 13.4, respectively (Additional file 1: Table S3).

\section{Test of natural sediments}

Physico-chemical characterisation of natural sediments Results of the physical and chemical characterization of river and lake sediment samples are shown in Table 4 and Additional file 1: Table S2 where chemicals with lower concentrations in samples are displayed as addition to Table 4. Concentrations of hazardous substances in natural sediments were evaluated against TEC - threshold effect concentration and PEC-the probable effect concentration [26] and the Serbian sediment target values (Serbian TV)/Serbian maximum allowable concentrations (Serbian MAC) [35]. TEC and Serbian $\mathrm{TV}$ are values below which harmful effects are unlikely to happen and can be described as long-term objectives of good ecological sediment status, while PECs and Serbian MAC are values above which harmful in situ effects are most likely to be observed.

Basic properties of natural sediment samples varied: river sediments contained higher proportions of sand (close to or higher than 70\%) compared to samples from Ludaš lake (45.3-64.3\%). Small particles and organic matter content was higher in samples J15, K16 and L1719 compared to samples from Tamiš (T6-T14).

The upper threshold values (PEC and Serbian MAC) for hazardous substances have been surpassed in the following samples: heptachlor epoxide in T6 and T7; mineral oils in K16 and L17; metal concentrations in T8 and L17 (Hg); T8-T11, L17 and L18 (As); L17 (Ni, Zn, Cr and $\mathrm{Cu}$ ). Metals were detected in almost every sample, except for Cd in T12, J15 and L17 and Pb, Hg and As in K16. In all samples except J15 and L18, mineral oils surpassed

Table 2 Average coefficients of variation (CV\%) of growth parameters in tested sediments and average minimum significant differences (MSD\%) in seven sediment contact tests

\begin{tabular}{|c|c|c|c|c|}
\hline \multirow[t]{2}{*}{ Growth parameters } & \multicolumn{2}{|c|}{ CV\% in tested samples $(n=19)$} & \multicolumn{2}{|c|}{ MSD $\%$ of tests $(n=7)$} \\
\hline & Average & Range (min-max) & Average & Range (min-max) \\
\hline wFW10_-final whorl fresh weight $(\mathrm{mg}), \mathrm{d} 10$ & 12.8 & $(3.5-26.7)$ & 22.8 & $(15-38.6)$ \\
\hline RGR — relative growth rate based on wFW, (0-10 days) & 20.4 & $(2.4-82.5)$ & 24.6 & $(12.8-47.7)$ \\
\hline sFW—shoot fresh weight (mg) & 26.4 & $(9.1-55.4)$ & 32.7 & $(18.9-60.7)$ \\
\hline$s L$-shoot length $(\mathrm{mm})$ & 18.1 & $(5.96-32.1)$ & 26.8 & $(12.6-41.3)$ \\
\hline rFW_root fresh weight (mg) & 39.5 & $(8.4-138.4)$ & 103.8 & $(32.5-200.6)$ \\
\hline $\mathrm{rL}$-root length (mm) & 38.2 & $(10.4-66.9)$ & 140.3 & $(43.7-380)$ \\
\hline rFW/sFW_root-shoot ratio (fresh weight) & 42.9 & $(3-145.9)$ & & \\
\hline rL/sL-root-shoot ratio (length) & 33.4 & $(7.3-67.5)$ & & \\
\hline
\end{tabular}

Standard growth parameter according to ISO 16191 [22] 
Table 3 Inhibition values (\%) based on RGR and other M. aquaticum growth parameters in different formulations of artificial sediments

\begin{tabular}{|c|c|c|c|c|c|}
\hline \multirow[t]{2}{*}{ Parameter } & \multicolumn{5}{|c|}{ Artificial sediments } \\
\hline & A1 & A2 & A3 & A4 & A5 \\
\hline \multicolumn{6}{|l|}{ Inhibition based on growth parameters (1\%) } \\
\hline RGR & $44.6^{*}$ & $45.3^{*}$ & $-31.5^{*}$ & -16 & -5 \\
\hline wFWd10 & $36.8^{*}$ & 33.6 & -39.9 & -15.6 & 1.03 \\
\hline sFW & 58.3 & 45.1 & $-91.6^{*}$ & -22.4 & -21 \\
\hline$s L$ & 25.4 & 23.6 & $-58.2^{*}$ & -9 & -13.5 \\
\hline rFW & 11 & 42.2 & $-84.8^{*}$ & $-82.5^{*}$ & 2.6 \\
\hline$r L$ & 21.6 & -4.7 & $-101.8^{*}$ & $-70.1^{*}$ & 13.4 \\
\hline $\begin{array}{l}\text { M. aquaticum growth inhibition } 1 \%_{R G R} \text { above or below the } \\
\text { toxicity threshold according to }[13]\end{array}$ & $\uparrow$ & $\uparrow$ & $\downarrow$ & $\downarrow$ & $\downarrow$ \\
\hline Sand, $\%$ & 78 & 69 & 47 & 30 & 20 \\
\hline Silt and clay, \% & 20 & 20 & 47 & 64 & 74 \\
\hline Org. matter, \% & 1 & 10 & 5 & 5 & 5 \\
\hline
\end{tabular}

A1-A5 artificial sediments with different organic matter, sand silt and clay content. All artificial samples contained $1 \% \mathrm{CaCO}_{3}$

$\uparrow$ Above the toxicity threshold $\downarrow$ below the toxicity threshold

RGR, relative growth rate; $w F W$, whorl fresh weight at d10; sFW, shoot fresh weight; sL, shoot length; rFW, root fresh weight; rL, root length

*Significantly different from the corresponding test control (one-way ANOVA followed by $t$ test, $p \leq 0.05$ )
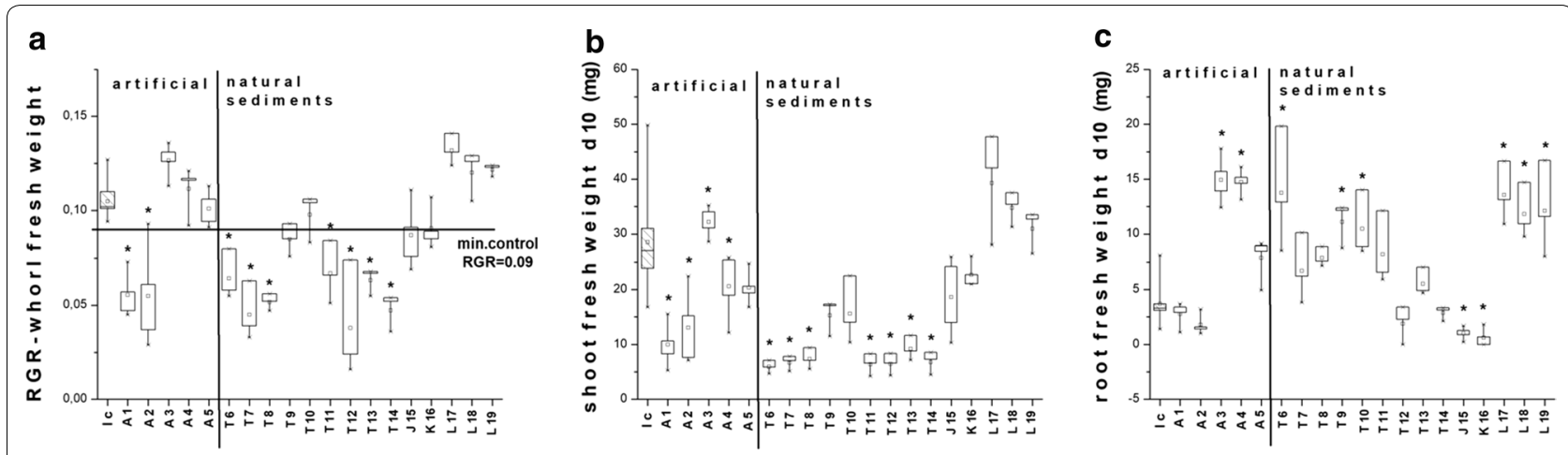

Fig. 1 Myriophyllum aquaticum growth in tested sediments compared to the long-term laboratory control. a Relative growth rate based on whorl fresh weight, b shoot fresh weight, $\mathbf{c}$ root fresh weight (Samples A1-5: artificial sediments with various organic matter, sand and fine particle content. Natural samples: T6-14 river Tamiš; 115 river Jegrička; K16 river Krivaja; L17-19 lake Ludaš. RGR, relative growth rate based on whorl fresh weight. [*Significantly different from the long-term control (one-way ANOVA followed by t test, $p \leq 0.05$ )]. All data on plant responses compared to test control and the long-term control are available in Additional file 1:Table S3)

TEC and Serbian TV (or even PEC and Serbian MAC in samples K16 and L17). In general, based on chemical analysis the river Tamiš (T6-T14), Jegrička (J15), Krivaja (K16), L18 and L19 lake Ludaš sediments can be regarded as low to moderately contaminated, while the L17 Ludaš lake sediment can be regarded as highly contaminated due to high metal concentrations and mineral oil content (Table 4, Additional file 1: Table S2 and [36-39]).

The M. aquaticum contact tests of natural sediments Plant whorl RGRs in all natural sediments except one (L17) were lower compared to test control (Table 4 and Additional file 1: Tables S2 and S3). If the threshold of $20 \%$ inhibition is applied, eight out of 14 natural sediment samples could be potentially classified as toxic compared to test control (Table 4) and seven compared to the long-term laboratory control (Fig. 1 and Additional file 1: Table S3).

\section{Additional growth parameters to standard RGR}

In artificial sediments, growth parameters followed the pattern of RGR responses (Table 3, Fig. 1 and Additional file 1: Table S3). In A1 and A2 samples (with $1 \%$ and $10 \%$ of organic matter, respectively), growth was impaired compared to control based on all growth parameters except for $\mathrm{rL}$ in A2. In artificial sediments with sand and 


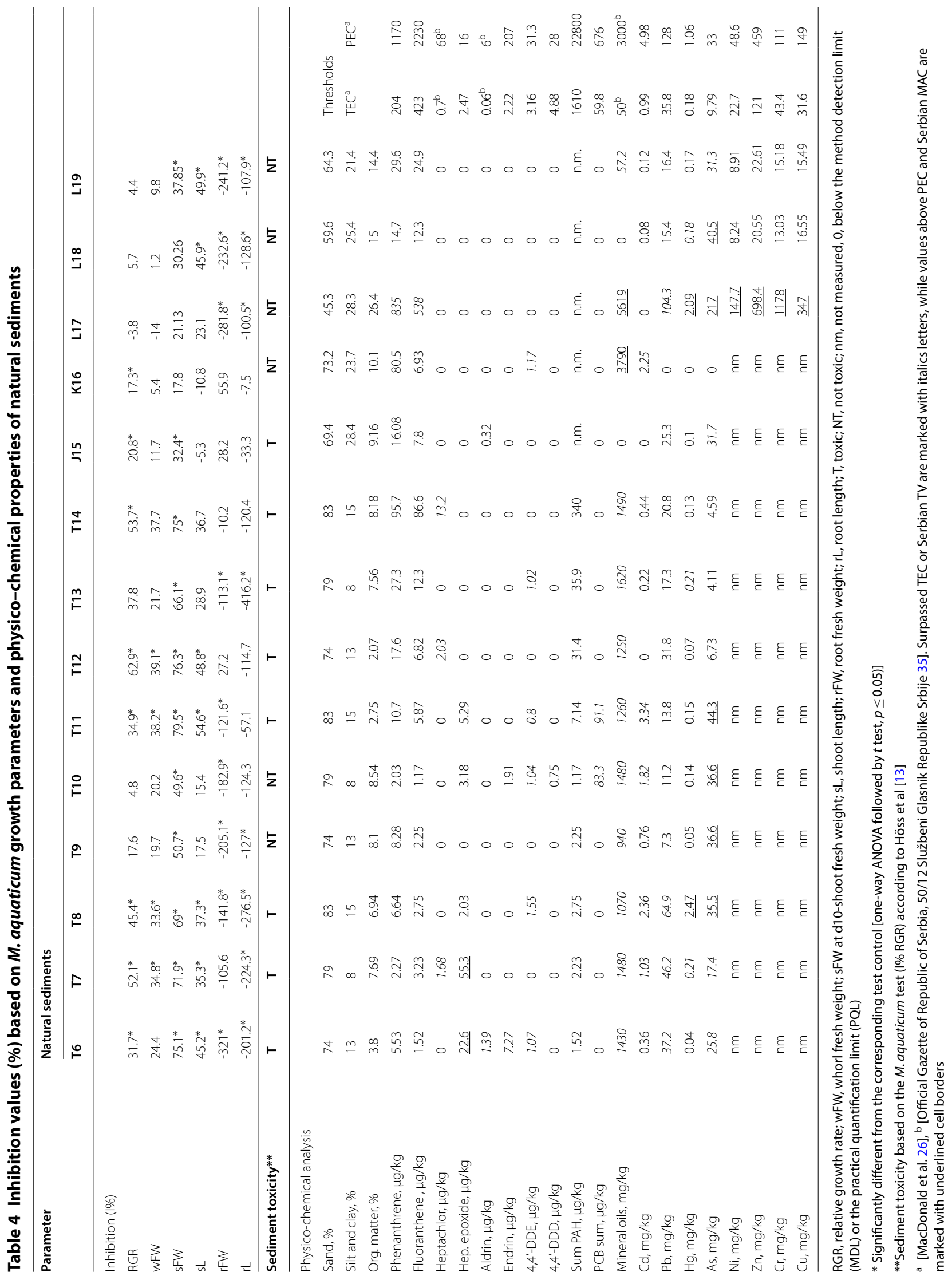


clay variations (A3-A5) plant shoot and root growth was stimulated compared to control (except rFW and $\mathrm{rL}$ in A5-highest clay content).

In natural samples, inhibition compared to control of shoot fresh weight (sFW) and length (sL) was observed on one side and stimulation of root FW and L on the other, with a few exceptions (Table 4, Fig. 1 and Additional file 1: Tables S2 and S3). Root-shoot ratio based on FW and L in the majority of the artificial and natural samples was higher than in the corresponding test control, as well as the long-term control (Additional file 1: Table S3).

\section{Multivariate analysis}

To better explain the relationship between $M$. aquaticum growth parameters and physico-chemical parameters analyzed in sediments and to distinguish between effects of non-toxic environmental factors and toxic substances in samples, a principal component analysis was carried out. Data included in the analysis are displayed in Additional file 1: Table S4.

Figure 2 shows relationships between observed variables-inhibitions or stimulations based on growth parameters and sediment physico-chemical parameters. The first two dimensions F1 and F2 explained 51.38\% of the variability of the initial dataset (eigenvalues are shown in Additional file 1: Table S5). According to correlation values (displayed in Table 5), inhibitions based on RGR, sFW and sL were strongly correlated between each other and with sand content, but also, a significant negative correlation was found between the same growth parameters and silt and clay content (correlation values were as follows: $-0.688 ;-0.809$ and -0.663 , respectively). For the presented data set, this suggests that as silt and clay increase, inhibition based on RGR, sFW sL decrease indicating that better plant growth (based on RGR, shoot FW and L) may be caused by higher silt and clay content in sediments. The PCA showed no significant correlation between $\mathrm{rFW}$ and small particles and sand content, while the correlation between $\mathrm{rL}$ and silt and clay content was significant (0.469). Root FW was more correlated with concentrations of $\mathrm{As}, \mathrm{Pb}, \mathrm{Hg}$, aldrin, endrin and organic matter (OM) content (than to silt and clay content). Low and insignificant correlation values were found between the growth parameters on one side and heptachlor, heptachlor epoxide, $\mathrm{Cd}, \mathrm{Pb}$ and $\mathrm{As}$ on the other. A correlation between OM content on one side and phenanthrene, fluoranthene, mineral oils, $\mathrm{As}, \mathrm{Pb}$ and $\mathrm{Hg}$ on the other was also observed.

Figure 2 also shows relationships between sediment samples. Sediments A1, A2, J15 and K16 are grouped around high inhibition values based on root FW, while sediments A3, A4 and A5 are grouped around high values of silt and clay content. High arsenic concentrations and OM content are most prominent in samples L17-19. The Tamiš sediments (T6-T14) are grouped around high inhibition values based on RGR, sFW and SL.

Results of the best approximating generalized linear models (GLMs) are shown in Additional file 1: Table S6. The results of GLMs selection procedure suggested that growth inhibition based on RGR, wFW, sFW was affected by the content of sand and fine particles in sediments. A similar conclusion could be drawn regarding $\mathrm{sL}$ and $\mathrm{rL}$; however, the low explanatory power of these models (low adjusted R-squared values) necessitates the caution when drawing conclusions. Additional environmental factors that significantly affected plant growth were organic matter content (for RGR, wFW and rFW inhibition), 4, $4^{\prime}$-DDD (in the RGR model), aldrin (affected rFW) and $4,4^{\prime}$-DDE (affected root L inhibition). The explanatory power of all final selected models (adjusted multiple R-squared) was between 0.63 and 0.17 .

\section{Discussion}

The inherent variability of the Myriophyllum aquaticum sediment contact test

According to the ISO protocol [22], an average relative growth rate (RGR) based on whorl FW in controls (of statistical replicates with three plants per pot) at the end of the test should be $\geq 0.09$ per day. An additional validity criterion RGR CV in control $\leq 15 \%$ is suggested based on the results of the International ring test [16, 22] and the proposed range of the initial whorl weight is aiming to minimize the variability of the plant material within controls and treatments.

Results of the international ring test [16] showed that RGR is a robust and reproducible parameter: the average control response in 14 tests was $0.135(0.106-0.2)$ and the average CV\% was 7\% (0.89-15.4\%). However, from 21 laboratories initially included, three failed to achieve the minimum RGR and four had difficulties with test performance or laboratory conditions; hence, seven tests were excluded from the calculation of results of the inter-laboratory test.

Our study provides data for 7 tests with an average test RGR 0.105 (ranging from 0.094 to 0.127 ) and CV\% $11.01 \%$ (ranging from 6.9 to $15.1 \%$ ). Individual replicate RGRs $(n=30)$ range from 0.079 to 0.149 and their average value and $C V \%$ is 0.106 and $15.04 \%$, respectively. Experience of the authors is that test validity criteria for achieving an average RGR per test of minimum 0.09 is easily achievable, but the inherent variability of this parameter (RGR CV\% in controls) seems higher than $15 \%$ and in approximately $30 \%$ of cases may not be achieved without excluding outliers, which can influence result interpretation. Even with the exclusion of very few 


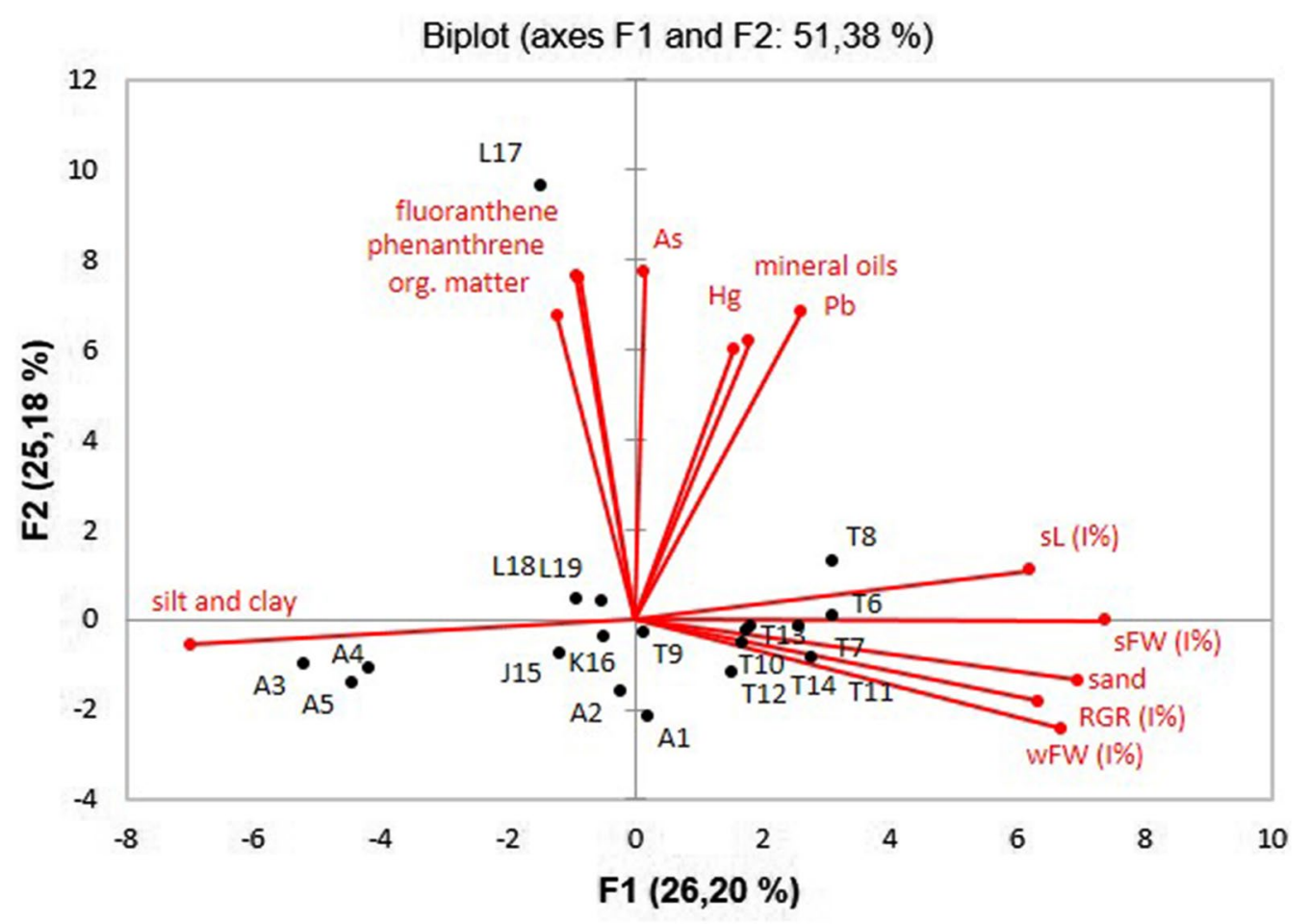

\section{- Active variables - Active observations}

Fig. 2 PCA based on M. aquaticum growth responses and physico-chemical parameters in sediments (Inhibitions based on RGR (I\%) —relative growth rate, wFW (I\%) — whorl fresh weight, sFW (1\%) — shoot fresh weight, sL (1\%)—shoot length, rFW (1\%)—root fresh weight; A1-5: artificial sediments with different organic matter, sand and fine particle content. Natural samples: T6-14 Tamiš; J15 Jegrička; K16 Krivaja; L17-19 Ludaš)

outliers, thirty replicate control RGR values range from 0.079 to 0.149 which is approximately $25 \%$ lower and $40 \%$ higher than the average test RGR value. Bearing this in mind, it would, perhaps, be more realistic not to expect such low natural variability of the plant's RGRs which could also influence the minimum statistical difference of tests and consequently the setting of a toxicity threshold of the test.

The average MSD\% of seven tests in this study (in tests with artificial as well as natural sediments) based on calculations of RGR was $24.6 \%$ ranging from 12.8 to $47.7 \%$. Höss et al. [13] recorded a mean minimal detectable difference (MDD) 14.4\% (9.2-20.1\%) for M. aquaticum RGR in tests of sediments with low anthropogenic contamination. The MDDs in the international ring test, in tests with the reference substance (3,5-dichlorophenol) ranged from 5.5 to $28.5 \%$ with one value (51.3\%), excluded as an outlier, while in tests with natural sediments with nickel chloride MDDs ranged from 5.8 to $28.8 \%$. It was concluded that the test system is able to significantly distinguish inhibitory effects of $12.9-15.1 \%$ on average and $27 \%$ at least. Feiler et al. [13] used a slightly contaminated natural sediment (instead of an artificial sediment) as a negative control in testing 21 natural sediments and stated that the recalculation of the maximal tolerable inhibition had no influence on the toxicity threshold of $20 \%$.

\section{The sediment contact tests Tests of artificial sediments with different $O M$, sand and clay content}

Our study confirmed that the structure of sediments affects $M$. aquaticum growth and therefore may influence result interpretation in terms of toxicity of tested samples. Tests of artificial sediments (A1-A5) with different proportions of organic matter, silt and clay significantly affected plant growth. Additionally, PCA and GLM showed a high correlation between the sediment structure and plant growth in artificial as well as natural sediment.

\section{Test of natural sediments}

Highest inhibitions of RGR ( $>40 \%)$ in natural samples were recorded in T7, T8, T12 and T14 (45.4\%-62.9\%). In case of $\mathrm{T} 7$ and $\mathrm{T} 8$, impaired growth could be attributed 


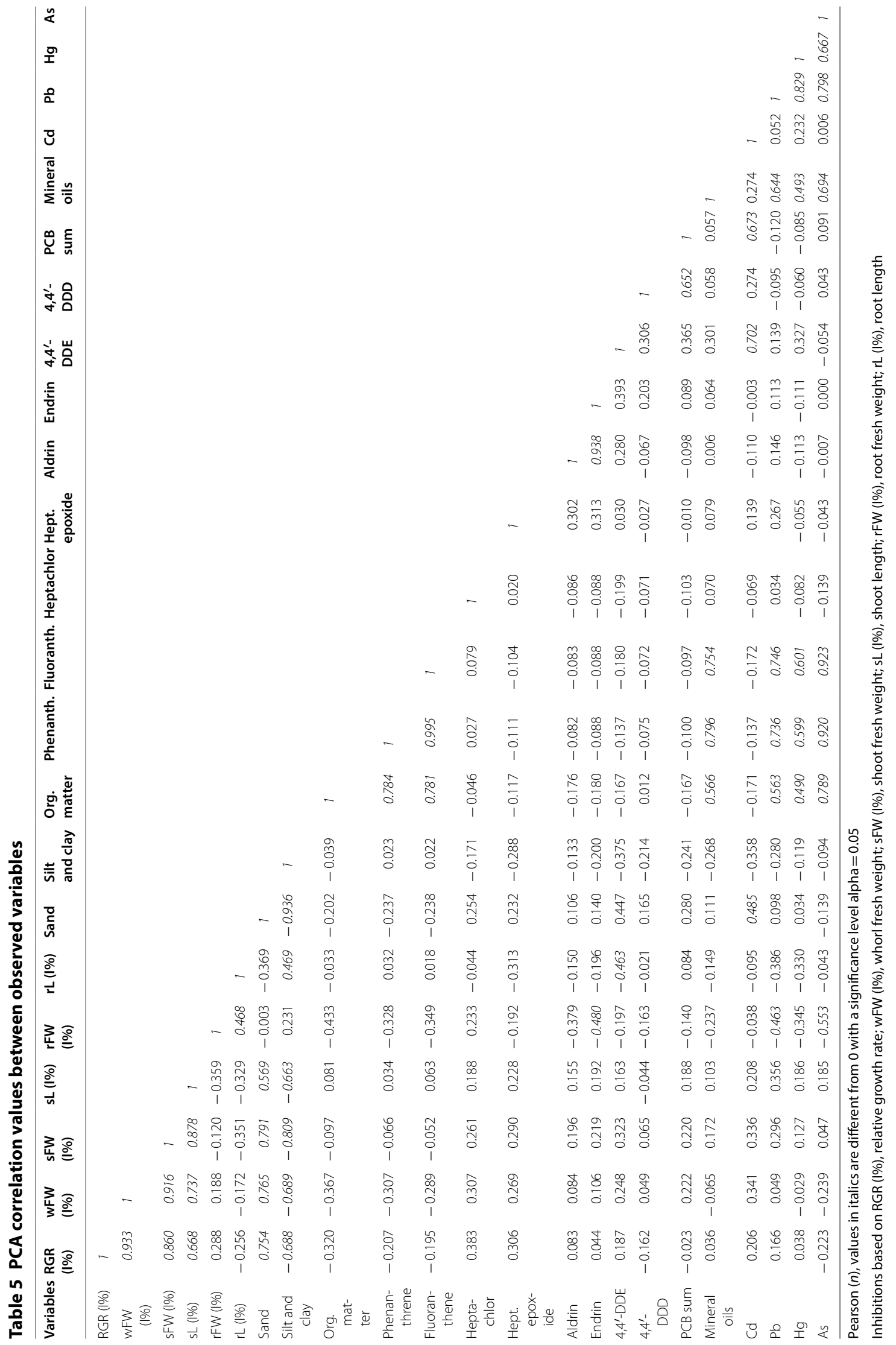


to high concentrations of $\mathrm{Cd}, \mathrm{Pb}, \mathrm{Hg}$, As and mineral oil, but in T12 and T14, only heptachlor and mineral oil content was above the TEC and Serbian TV thresholds. In $\mathrm{T} 12$ and $\mathrm{T} 14 \mathrm{~Pb}$ concentrations were elevated, but still under the threshold. The high growth inhibition in sample T12 could have been attributed to low OM content (2.07\%).

Inhibitions in the range $30-40 \%$ were recorded in samples T6, T11 and T13. In those samples, concentrations of six, four and three hazardous chemicals were above the TEC threshold, respectively. Also, heptachlor epoxide and As were above the PEC threshold in T6 and T11, respectively. Inhibitions in T6 and T11 were statistically significant, while inhibition in T13 was not. Grain size distribution in these samples was similar, while OM content was lower in $\mathrm{T} 6$ and $\mathrm{T} 11$ (3.8\% and $2.75 \%$, respectively) than in $\mathrm{T} 13(7.56 \%)$.

Inhibitions around $20 \%$ were recorded in samples T9, $\mathrm{J} 15$ and K16. In T9 and K16, the concentration of one hazardous substance was above TEC and one above PEC, per sample. The River Jegrička is designated as a protected area and consequently does not receive any direct input of industrial effluents, while the buffer zones should sufficiently protect the water body from agricultural runoff. However, the sample J15 $(I=20.8 \%)$ contained arsenic above TEC (close to PEC value) and organic pollutants, including several PAHs from the list of priority substances (Table 4, Additional file 1: Table S2 and [37]). If we apply the $20 \%$ toxicity threshold, this sample could be characterized as toxic. When we compare the same sample to the long-term control, inhibition is below $20 \%$. According to the available reports [38,39], a huge pressure on the Krivaja river comes from waste waters and agricultural fields and sediments from some sites are typically characterized by high mineral oil content and $\mathrm{Ni}$ concentrations. However, this time the chemical analysis did not include measuring of $\mathrm{Ni}$ in the $\mathrm{K} 16$ sample and the overall contamination of the sediment seemed lower than expected.

Inhibitions lower than $6 \%$ were recorded for samples T10, L17, L18 and L19 where a higher inhibition would have been expected based on chemical analysis and, for the Ludaš samples, biodiversity analysis [39]. Based on the report [39] even the most tolerant benthic macroinvertebrates were absent from the Ludaš samples. Sample T10 contained four hazardous substances above TEC and one above PEC, but inhibition was only $4.8 \%$. This sample, however, compared to other Tamiš samples contained the highest OM content (8.54\%). The only natural sediment sample that resulted with stimulation of RGR compared to test control was L17-the most toxic, based on chemical analysis.

Following the regulatory demands of Republic of Serbia [35], metal concentration in samples and not their bioavailable fraction should be reported, although various sediments may show different degrees of bioavailability for the same total metal content [40]. In that context, it was not established whether measured concentrations of metals in samples were bioavailable to $M$. aquaticum and whether structural properties of samples (such as OM content, for example) influenced their bioavailability. However, in some cases, low RGR inhibition $(<25 \%)$, which indicates non-toxic samples, was recorded in samples with high OM content (8-26.4\%), as opposed to higher inhibitions in samples characterized by low OM content and higher content of fine particles. Sample T12, for example, did not contain a high number of pollutants but the OM content was around $2 \%$ and plant growth inhibition was $62.9 \%$. High inhibition of growth (44.6\%) was also recorded in the artificial sediment containing no hazardous substances and $1 \%$ peat (Table 3). Direct comparison of the results of the chemical analysis and sediment contact tests in T10 $(I=4.8 \%)$ and T11 $(I=34.9 \%)$ indicates that inherent sediment properties influence the bioavailability and, consequently, the toxicity of sediment-bound pollutants. The higher OM content (8.54\%) in T10 could have influenced the bioavailability of pollutants resulting with low $M$. aquaticum growth inhibition, while T11 did contain slightly higher concentrations of metals than T10, but also lower OM content (2.75\%). Further, high RGR values in Ludaš lake samples could have been due to high OM content and low bioavailability of the present toxic substances, but they also could have been a result of higher silt and clay content that the test plant prefers.

Table 6 displays minimum and maximum values of $M$. aquaticum growth inhibitions, geochemical and chemical properties in natural sediment samples from Höss et al. [13], Feiler et al. [15] and this study. The two cited studies applied a test battery consisting of a number of tests in assessment of: ten samples of freshwater sediments with low contamination [13] and 21 natural samples with a broad variety of anthropogenic contamination [15].

Concentrations of hazardous substances in the study [13] compared to our study were generally lower, while the structure variations were more evident. On the other hand, chemical contamination in natural samples from [15] was more pronounced and varied more compared to the samples from our study. Silt and clay content in our natural samples ranged from 8 to $28.4 \%$, while it ranged from 36 to $97 \%$ and from 10.1 to $97.5 \%$ in the studies [13] and [15], respectively. Artificial sediments from our study varied from 20 to $74 \%$ in clay content and resulted with better growth of plants in samples with higher than $20 \%$ of clay.

Plant response in slightly contaminated samples in the study [13] ranged from a $23 \%$ stimulation to a 
Table 6 Minimum and maximum values of $M$. aquaticum growth inhibitions, geochemical and chemical properties of tested sediments in the present and cited studies $[13,15]$

\begin{tabular}{|c|c|c|c|c|c|c|c|c|}
\hline & \multirow{2}{*}{\multicolumn{2}{|c|}{$\frac{\text { Höss et al. [13] }}{\text { Natural sed. }}$}} & \multirow{2}{*}{\multicolumn{2}{|c|}{$\frac{\text { Feiler et al. [15] }}{\text { Natural sed. }}$}} & \multicolumn{4}{|c|}{ Own data } \\
\hline & & & & & \multicolumn{2}{|c|}{ Natural sed. } & \multicolumn{2}{|c|}{ Artificial sed. } \\
\hline & Min. & Max. & Min. & Max. & Min. & Max. & Min. & Max. \\
\hline $\begin{array}{l}\text { M. aquaticum growth inhibition } \\
\left(\left(1 \%_{\mathrm{RGR}}\right), \%\right.\end{array}$ & -23 & 17 & -6.4 & $42.2^{*}$ & -3.8 & $62.9^{*}$ & $-31.5^{*}$ & $45.3^{*}$ \\
\hline Sand, \% & 1.7 & 62.1 & 1.7 & 89.7 & 45.3 & 83 & 20 & 78 \\
\hline Silt and clay, $\%$ & 36.9 & 97 & 10.1 & 97.5 & 8 & 28.4 & 20 & 74 \\
\hline Organic matter, \% & 4.3 & 28 & 4.3 & 26.7 & 2.07 & 26.4 & 1 & 10 \\
\hline PCB sum, $\mu \mathrm{g} / \mathrm{kg}^{\mathrm{a}}$ & 1.1 & 43 & $<5$ & 286 & 0 & 91.1 & & \\
\hline PAH $\Sigma 16$ (US EPA), mg/kg & $<1$ & 5.3 & $<1$ & 509 & / & / & & \\
\hline PAH $\Sigma 9$ [26], mg/kg & / & / & 0.5 & 350 & $<0.1$ & 0.34 & & \\
\hline Mineral oils, mg/kg & $<100$ & 640 & / & / & 0 & 5619 & & \\
\hline $\mathrm{Cd}, \mathrm{mg} / \mathrm{kg}$ & $<0.3$ & 0.4 & $<0.3$ & 33 & 0 & 3.34 & & \\
\hline $\mathrm{Pb}, \mathrm{mg} / \mathrm{kg}$ & 0.5 & 53 & 7 & 480 & 0 & 104.3 & & \\
\hline $\mathrm{Hg}, \mathrm{mg} / \mathrm{kg}$ & 0.01 & 0.58 & 0.04 & 96 & 0 & 2.47 & & \\
\hline $\mathrm{As}, \mathrm{mg} / \mathrm{kg}$ & $<3$ & 14 & $<3$ & 73 & 0 & 217 & & \\
\hline $\mathrm{Ni}, \mathrm{mg} / \mathrm{kg}^{\mathrm{b}}$ & $<1$ & 35 & $<1$ & 110 & 8.24 & 147.7 & & \\
\hline $\mathrm{Zn}, \mathrm{mg} / \mathrm{kg}^{\mathrm{b}}$ & 1 & 205 & 19 & 4600 & 20.55 & 698.4 & & \\
\hline $\mathrm{Cr}, \mathrm{mg} / \mathrm{kg}^{\mathrm{b}}$ & 1 & 53 & 4 & 156 & 13.03 & 1178 & & \\
\hline $\mathrm{Cu}, \mathrm{mg} / \mathrm{kg}^{\mathrm{b}}$ & 1 & 58 & 4 & 3100 & 15.5 & 347 & & \\
\hline
\end{tabular}

* Statistically significant compared to control

${ }^{\text {a }}$ Measured only in T6-T14

b Measured only in L17-L19

$17 \%$ of inhibition of growth (inhibition was recorded in three of ten samples only, not significantly different from that in the control). M. aquaticum showed the highest growth rates in four samples (growth stimulation was approximately $20 \%$ compared to control) with high content of silt and clay (71-97\%), despite the slight contamination by metals. Additionally, the only sediment considered as moderately polluted was one of the samples with highest RGR. It was assumed that a part of the variability in slightly to moderately contaminated sediments is caused by structural properties of sediments implying that sediment natural characteristics can influence the interpretation of the results and consequently sediment quality assessment. Plant responses in the study [13] could partially be attributed to the natural inherent variability of the tested organism, as well.

Twelve of the 21 tested samples in the study [15] contained at least one hazardous substance above TEC and the upper threshold PEC, but only five samples resulted with growth inhibitions above $20 \%$, two of which contained none of the substances above TEC. The highest inhibition (42.2\%) was recorded in the sample with lowest silt and clay content (10.1\%) which was the only sample with such low small particles content and that was the only recorded inhibition above $30 \%$. However, according to their statistical analysis, structural properties of sediments did influence some of the organisms in the test battery, but the only variable that significantly related to the response of organisms was the toxic potential of organic chemicals. They also concluded that plants responded more to metal contamination than to other types of pollution.

Based on the results of the M. aquaticum sediment contact test in the present and the cited studies, it seems difficult to distinguish between effects of sediment-bound pollutants and structural properties of samples and therefore sediment toxicity to the test organism. Since natural samples vary not only in toxic substance concentrations, but also in geochemical structure, growth of the tested plants may be influenced by structural properties of sediments, as well. The present study, as well as literature data, showed that $M$. aquaticum is able to grow well in sediments with high content of silt, clay and/or OM content even when concentrations of trace metals are elevated, probably due to their low bioavailability in such sediments. Therefore, sediment inherent properties might considerably affect the sensitivity and reliability of the $M$. aquaticum sediment contact test. Thus, the addition of appropriate field-collected natural uncontaminated controls to 
standard artificial controls is recommended when available [28].

The number of analyzed pollutants in sediments tested in this study was limited; hence, plant growth could have been affected by the presence of non-identified pollutants, as well. Plant protection products could have been key toxicants responsible for observed growth inhibitions, bearing in mind the land use patterns in the vicinity of selected water bodies and high sensitivity of selected species to herbicides [41]. Similarly to our study, Feiler et al. [42] recorded insignificant $M$. aquaticum growth inhibition in a highly contaminated sample, growth stimulation in slightly to moderately contaminated samples and high inhibition in the slightly contaminated sample. The conclusion was that key toxicants causing plant growth inhibition in the sample must have been herbicides undetectable by chemical screening due to fast degradation. Studies of Stešević et al. [43] and Planojević et al. [44] attributed high inhibitions of $M$. aquaticum growth to very high concentrations of metals. It seems that $M$. aquaticum is sensitive to sediment contamination by trace metals and herbicides, but less sensitive to non-polar organic pollutants [13, 42-44]. Feiler et al. [15] applied a test battery consisting of five sediment contact tests (including the M. aquaticum test) and concluded that the chemical contamination of the tested sediments was in general proved by the test battery, but not by every single toxicity test applied in each sample. More importantly, they found that in sediments with low to medium chemical pollution, the toxicity was underestimated by the SQG approach.

Difficulties with result interpretation have been experienced in bioassays with invertebrate species as well. For example, de Deckere et al. [27] found that the Hyalella azteca sediment contact test (which is the only sediment contact tests applied in the Flemish monitoring program) is applicable for distinguishing toxic from non-toxic sediments, but not useful in determining the level of toxicity. Additionally, the lack of available ecotoxicological data for benthic organisms and plants hampers the development of environmental quality standards (EQS) for sediment [6].

\section{Additional growth parameters}

When methods in ecotoxicological testing are developed, a lot of effort is invested in finding the most appropriate endpoint, as it is not rare that an organism's response to toxic stress varies depending on the parameter observed [41]. Usually, the most sensitive, ecologically relevant and least variable parameter is preferred and the relative growth rate of a parameter is favored over parameters measured only at the end of the test, since it takes into account the length of the test and makes comparisons between the sensitivity of different species and tests possible $[28,45]$.

High variability of root FW and L [average values $34.2 \%$ and $44 \%$ in controls $(n=7)$ and $39.5 \%$ and $38.2 \%$ in tested sediments $(n=19)$ ] could have been influenced by numerous adventitious roots that $M$. aquaticum develops. The high variability of shoot and root parameters also influenced root-shoot ratio variability. Knauer et al. [46] reported lower variability in root development: $23 \%$ in standard artificial substrate and $24 \%$ in natural controls, but based on the length of the longest root only, in a single experiment with three replicates (seven plants per test pot). Hussner et al. [47] reported a lower range of root-shoot ratio (0.09-0.16) based on dry weight measurements. Knauer et al. [46] also recorded low CVs in uncontaminated natural sediments: 15 and $8 \%$ for final whorl FW and RGR, respectively. Our study did not show a consistently low variability for the same parameters in natural sediments with low contamination (Additional file 1: Tables S2 and S3).

The considerable root growth ( $>100 \%$ stimulation versus control) in natural moderately and highly contaminated sediments in this study may be associated with inherent sediment properties such as fine particle or organic matter, as well as with concentrations of trace metals. Whorl and shoot growth stimulation was also observed in uncontaminated and slightly contaminated natural sediments compared to the artificial control sediments by Feiler et al. [42], Knauer et al. [46] and Höss et al. [13]. Values of root-shoot ratios in Knauer et al. [46] were 4 and 4.3 in natural uncontaminated compared to standard artificial sediment, respectively, but this calculation was based on the longest root only.

Root fresh weight reflects on the overall plant fresh weight, so the major root stimulation in the natural samples significantly affected the inhibition values of RGR compared to control. If root growth had not been stimulated so much in the natural sediments, the overall plant growth inhibitions in samples would have been higher. This especially stands for Ludaš samples (L17-19). Results of tests of artificial sediments A1-A5 indicated that $\mathrm{OM}$ content does not affect root growth significantly, but fine particle content does, since significant root growth stimulation happened in A3 and A4 samples with $47 \%$ and $64 \%$ (but not in sample with $74 \%$ ) of fine particles. However, root growth was not stimulated in all natural samples with high percent of fine particles; so, no general causality of root stimulation and fine particles content was found (based on test results, as well as the PCA). Root FW was stimulated in Tamišs sediments with higher content of fine particles (8-15\%) than in control, while it was not stimulated in samples J15 and K16 where 
the content of fine particles was even higher (28.4 and 23.7\%, respectively). Nevertheless, root FW and L were extremely stimulated in three Ludaš samples where silt and clay content was $28.3,25.4$ and $21.4 \%$, respectively.

Average MSD\% values of tests in this study based on whorl FWd10, sFW and sL (22.8, 32.7 and $26.8 \%$, respectively) were relatively close to the MSD\% of tests based on RGR (24.6\%) and could be considered relatively low. Additionally, shoot and root growth (based on FW and $\mathrm{L}$ basis) showed an interesting pattern in the majority of the tested natural sediments compared to control (stimulation of root growth opposed to inhibition of shoot growth). Results also indicated that root growth may be stimulated in sediments with higher silt and clay content. Nevertheless, analysis of additional parameters did not help in differentiating between the impact of sedimentbound substances and inherent sediment properties and because of that their use is not essential.

\section{Conclusions and recommendations}

The $M$. aquaticum sediment contact test was not developed and intended to be applied as a stand-alone tool but as one of the toxicity tests applied in concert, as a line of evidence in the weight of evidence approach in sediment assessment. Acknowledging that, the following conclusions and recommendations derive from the results of the present study.

As this study showed that sediment structure has a significant impact on plant growth, the use of adequate control sediments might be crucial. To avoid false-positive but also false-negative results of the contact test, it can be recommended to compare RGRs recorded in test samples not only to the corresponding standard test control, but also to the long-term average laboratory control. Other negative controls recommended for use are uncontaminated natural samples and modified standard artificial sediments. Since uncontaminated natural control sediments are not often available, it would be beneficial to prepare appropriate alternative laboratory control sediments and include them in tests along with the standard control. The additional control should be more similar to tested natural sediments in structure to minimize the difference between general environmental conditions in tested and control sediments and raise the ecological realism and reliability of the test.

If the aim is to interpret test results as accurately as possible, the inherent variability of the standard endpoint relative growth rate based on whorl FW should be taken into account. Applying the stringent toxicity threshold of $20 \%$ is not always advisable. Based on the minimum and maximum values of the replicate RGRs in this study that correspond to a $\pm 25-40 \%$ difference compared to the average test control value $(0.105)$ and the average replicate control value (0.104), MSD\% of tests might be generally higher than expected and re-evaluating the toxicity threshold might be of interest. Our findings lead to the recommendation that the threshold value is acceptable to declare toxicity of a sample, provided it was accompanied with proven statistical significance of difference between test and the control RGR values obtained by powerful and sensitive statistical test with MSD (\%) values preferably $<25 \%$.

The use of RGR plant whorl FW seems to be an adequate parameter in the $M$. aquaticum sediment contact test, since it proved to have acceptable variability and reproducibility. The analysis of other growth parameters revealed a particular growth pattern and gave an insight into plant growth in artificial and natural samples, but did not help in differentiating between the impact of sediment-bound substances and inherent sediment properties. The analysis of growth responses other than the standard parameter may, therefore, not be reasonable, especially bearing in mind their higher variability and usually higher MSD\% in tests when statistical analysis is based on them.

In conclusion, the ecological relevance of the Myriophyllum aquaticum sediment contact test is high, since the rooted plant has direct contact with the sediment. The test is robust and easy to conduct, suitable for screening and assessment of natural potentially contaminated sediments. However, to make a test more fit for purpose, the interpretation of the results must acknowledge the complexity of experimental set-up and the influence of sediment structural properties on plant growth. The results of this study might contribute to the wider application of the M. aquaticum sediment contact tests, in line with the ongoing initiatives to implement the effect-based methods to link the ecological and chemical status of waters under the Water Framework Directive and minimize the danger of overlooking risk from unmeasured hazardous substances and chemical mixtures.

\section{Additional file}

Additional file 1. Additional data.

Authors' contributions

TT has been responsible for the concept of the manuscript and drafted the manuscript. VM and the first author conducted laboratory tests, TJ performed the multivariate linear regression analysis, AT, DK, JT performed physicochemical analysis and IT improved the manuscript and contributed specific aspects. All authors read and approved the final manuscript.

\footnotetext{
Author details

${ }^{1}$ Department of Biology and Ecology, LECOTOX-Laboratory for Ecotoxicology, Faculty of Sciences, University of Novi Sad, Trg Dositeja Obradovića 2, 21000 Novi Sad, Serbia. ${ }^{2}$ Department of Chemistry, Biochemistry
} 
and Environmental Protection, Laboratory for Chemical Environmental Analysis "Dr Milena Dalmacija", University of Novi Sad, Trg Dositeja Obradovića 3, 21 000 Novi Sad, Serbia.

\section{Acknowledgements}

The study was financially supported by the Ministry of Education, Science and Technological Development of the Republic of Serbia via Grant No. 173037 and the SOLUTIONS project, funded by the EU FP 7 (FP7-ENV-2013-two-stage Collaborative project) under Grant Agreement Number 603437.

\section{Competing interests}

The authors declare that they have no competing interests.

\section{Availability of data and materials}

All data generated or analyzed during this study are included in this published article (and its additional file).

\section{Consent for publication}

Not applicable.

Ethics approval and consent to participate

Not applicable.

\section{Funding}

Ministry of Education, Science and Technological Development of the Republic of Serbia, Grant No. 173037.

The SOLUTIONS project, funded by the EU FP 7 (FP7-ENV-2013-two-stage Collaborative project) under Grant Agreement Number 603437.

\section{Publisher's Note}

Springer Nature remains neutral with regard to jurisdictional claims in published maps and institutional affiliations.

Received: 11 December 2018 Accepted: 25 February 2019

Published online: 12 March 2019

\section{References}

1. Dueri S, Castro-Jiménez J, Comenges JMZ (2008) On the use of the partitioning approach to derive Environmental Quality Standards (EQS) for persistent organic pollutants (POPs) in sediments: a review of existing data. Sci Total Environ 403(1-3):23-33. https://doi.org/10.1016/j.scito tenv.2008.05.016

2. Marziali L, Rosignoli F, Dragoa A, Pascariello S, Valsecchi L, Rossarob B, Guzzella L (2017) Toxicity risk assessment of mercury, DDT and arsenic legacy pollution in sediments: a triad approach under low concentration conditions. Sci Total Environ 593-594:809-821. https://doi.org/10.1016/j. scitotenv.2017.03.219

3. Tueros I, Borja Á, Larreta J, Rodríguez JG, Valencia V, Millán E (2009) Integrating long-term water and sediment pollution data, in assessing chemical status within the European Water Framework Directive. Mar Pollut Bull 58(9):1389-1400. https://doi.org/10.1016/j.marpolbul.2009.04.014

4. Directive 2000/60/EC of the European Parliament and of the Council of 23 October 2000 establishing a framework for Community action in the field of water policy (The Water Framework Directive). Official Journal of the European Communities, L 327/1-72

5. Voulvoulis N, Arpon KD, Giakoumis T (2017) The EU Water Framework Directive: from great expectations to problems with implementation. Sci Total Environ 575:358-366. https://doi.org/10.1016/j.scito tenv.2016.09.228

6. Brils J (2008) Sediment monitoring and the European Water Framework Directive. Annali dell'Istituto Superiore Di Sanita 44(3):218-223

7. Mair R (2017) Relevance of sediment management in the context of river basin management planning. Raimund MAIR, European Commission, DG ENV. 10th International SedNet Conference. 14-17 June 2017, Genoa, Italy. https://sednet.org/wp-content/uploads/2017/07/2017-pres1 -2-Raimund-Mair.pdf. Accessed 2 Dec 2018
8. The European Sediment Network (SedNet) (2016) SedNet: the evolving, European Sediment Network. June 2016. https://sednet.org/wp-conte nt/uploads/2018/02/Presentation-SedNet-28-June-2016.pdf. Accessed 2 Dec 2018

9. Directive 2008/105/EC of the European Parliament and of the Council of 16 December 2008 on environmental quality standards in the field of water policy, amending and subsequently repealing Council Directives 82/176/EEC, 83/513/EEC, 84/156/EEC, 84/491/EEC, 86/280/EEC and amending Directive 2000/60/EC of the European Parliament and of the Council

10. Directive 2013/39/EU of the European Parliament and of the Council of 12 August 2013 amending Directives 2000/60/EC and 2008/105/EC as regards priority substances in the field of water policy

11. Chapman PM (2007) Determining when contamination is pollutionweight of evidence determinations for sediments and effluents. Environ Int 33(4):492-501. https://doi.org/10.1016/j.envint.2006.09.001

12. Long RE, Chapman MP (1985) A sediment quality triad: measures of sediment contamination, toxicity and infaunal community composition in Puget sound. Mantle Pollut Bull 16(10):405-415. https://doi. org/10.1016/0025-326X(85)90290-5

13. Höss S, AhlfW, Fahnenstich C, Gilberg D, Hollert H, Melbye K, Meller M, Hammers-Wirtz M, Heininger P, Neumann-Hensel H, Ottermanns R, Ratte H-T, Seiler B, Spira D, Weber J, Feiler U (2010) Variability of sedimentcontact tests in freshwater sediments with low-level anthropogenic contamination-determination of toxicity thresholds. Environ Pollut 158(9):2999-3010. https://doi.org/10.1016/j.envpol.2010.05.013

14. European Chemical Agency (ECHA) (2013) Principles for environmental risk assessment of the sediment compartment. In: Tarazona, JV, Versonnen B, Janssen C, De Laender F, Vangheluwe M, Knight D, eds. Proceedings of the topical scientific workshop. Helsinki, 7-8 May 2013

15. Feiler U, Hoss S, AhlfW, Gilberg D, Hammers W, Hollert H, Meller M, Neumann-Hensel H, Ottermanns R, Siler TB, Spira D, Heiningery P (2013) Sediment contact tests as a tool for the assessment of sediment quality in German waters. Environ Toxicol Chem 32(1):144-155. https://doi. org/10.1002/etc.2024

16. Feiler U, Ratte M, Arts G, Bazin C, Brauer F, Casado C, Dören L, Eklund B, Gilberg D, Grote M, Gonsior G, Hafner C, KopfW, Lemnitzer B, Liedtke A, Matthias U, Okos E, Pandard P, Scheerbaum D, Schmitt-Jansen M, Stewart K, Teodorovic I, Wenzel A, Pluta HJ (2014) Inter-laboratory trial of a standardized sediment contact test with the aquatic plant Myriophyllum aquaticum (ISO 16191). Environ Toxicol Chem 33(3):662-670. https://doi. org/10.1002/etc.2483

17. Wernersson A, Carere M, Maggi C, Tusil P, Soldan P, James A, Sanchez W, Dulio V, Broeg K, Reifferscheid G, Buchinger S, Maas H, Van Der Grinten E, O'Toole S, Ausili A, Manfra L, Marziali L, Polesello S, Lacchetti I, Mancini L, Lilja K, Linderoth M, Lundeberg T, Fjällborg B, Porsbring T, Larsson DGJ, Bengtsson-Palme J, Förlin L, Kienle C, Kunz P, Vermeirssen E, Werner I, Robinson DC, Lyons B, Katsiadaki I, Whalley C, den Haan K, Messiaen M, Clayton H, Lettieri T, Carvalho RN, Gawlik BM, Hollert H, Di Paolo C, Brack W, Kammann U, Kase R (2015) The European technical report on aquatic effect-based monitoring tools under the water framework directive. Environmental Sciences Europe 27:7. https://doi.org/10.1186/s1230 2-015-0039-4

18. Brack W, Escher BI, Müller E, Schmitt-Jansen M, Schulze T, Slobodnik J, Hollert H (2018) Towards a holistic and solution-oriented monitoring of chemical status of European water bodies: how to support the EU strategy for a non-toxic environment? Environ Sci Eur 30:33. https://doi. org/10.1186/s12302-018-0161-1

19. International Organization for Standardization (ISO) (2016) Soil quality - contact test for solid samples using the dehydrogenase activity of Arthrobacter globiformis. ISO 18187:2016

20. International Organization for Standardization (ISO). (2010) Water quality-determination of the toxic effect of sediment and soil samples on growth, fertility and reproduction of Caenorhabditis elegans (Nematoda) ISO 10872:2010

21. International Organization for Standardization (ISO) (2013) Water quality-determination of toxicity of fresh water sediments using Hyalella azteca. ISO 16303:2013

22. International Organization for Standardization (ISO) (2013) Water quality-determination of the toxic effect of sediment on the growth behaviour of Myriophyllum aquaticum. ISO 16191:2013. Geneva, Switzerland 
23. Bui TKL, Do Hong LCD, Combi T, Lara-Martin PA, Casado-Martínez MC, Werner I (2016) Sediment quality assessment in Ho Chi Minh City canals. SETAC Europe 26th annual meeting. 22-26 May 2016. Nantes, France. Poster presentation. http://www.microbiotests.be/posters/SETAC_2016_ HCMC.pdf. Accessed 2.12.2018

24. de Castro-Català N, Kuzmanovic M, Roig N, Sierra J, Ginebreda A, Barceló D, Pérez S, Petrovic M, Picó Y, Schuhmacher M, Muñoz I (2015) Ecotoxicity of sediments in rivers: invertebrate community, toxicity bioassays and the toxic unit approach as complementary assessment tools. Sci Total Environ 540:297-306. https://doi.org/10.1016/j.scitotenv.2015.06.071

25. Diepens NJ, Arts GHP, Brock CMT, Smidt H, Paul J, Van Den Brink JP, Van Den Heuvel-Greve JM, Koelmans AA (2014) Sediment toxicity testing of organic chemicals in the context of prospective risk assessment: a review. Crit Rev Environ Sci Technol 44(3):255-302. https://doi.org/10.1080/01496 395.2012.718945

26. MacDonald DD, Ingersoll CG, Berger TA (2000) Development and evaluation of consensus-based sediment quality guidelines for freshwater ecosystems. Environ Toxicol Chem 19(5):1403-1413. https://doi.org/10.1002/ etc.5620190524

27. de Deckere E, De Cooman W, Leloup V, Meire P, Schmitt C, von der Ohe PC (2011) Development of sediment quality guidelines for freshwater ecosystems. J Soils Sediments 11(3):504-517. https://doi.org/10.1007/ s11368-010-0328-x

28. European Food Safety Authority (EFSA) (2015) Scientific opinion on the effect assessment for pesticides on sediment organisms in edge-offield surface water EFSA panel on plant protection products and their residues. EFSA J 13(7):4176

29. International Organization for Standardization (ISO) (2009) Soil quality — determination of particle size distribution in mineral soil materialmethod by sieving and sedimentation. ISO 11277:2009

30. NEN 5754 Bodem (1992) Bapaling van het gehalte aan organische stof in grond volgens gloeiverliesmethode

31. Teodorović l, Maurić N (2003) TesToks, verzija 1.0. Zadužbina Andrejević i Nacionalni komitet IAD-a Srbije i Crne Gore

32. Burnham KP, Anderson DR (2004) Multimodel inference: understanding AIC and BIC in model selection. Sociol Methods Res 33:261-304. https:// doi.org/10.1177/0049124104268644

33. Venables WN, Ripley BD (2002) Modern applied statistics with S, 4th edn. Springer, New York. ISBN 0-387-95457-0

34. Zhang D (2018) rsq: R-Squared and Related Measures. R package version 1.1. https://CRAN.R-project.org/package=rsq

35. Official Gazette of Republic of Serbia, 50/12 Službeni Glasnik Republike Srbije (2012) Uredba o graničnim vrednostima zagađujućih materija u površinskim, podzemnim vodama i sedimentu i rokovima za njihovo dostizanje. Vlada Republike Srbije. Sl. glasnik RS, br. 50/2012

36. Teodorović l. (ed.) (2010) Studija hemijskog, fizičkog i biološkog statusa reke Tamiš (06SER02/03/007-8). U okviru susedskog programa Rumunija—Srbija EKO-STATUS REKE TAMIŠ, Univerzitet u Novom Sadu Prirodno-matematički fakultet
37. Tubić A, Leovac A, Hrubik J, Glišić B, Kaišarević S, Ivančev-Tumbas I, Kovačević R (2013) Toxicological profiles assessment of the water and sediments from the Krivaja and Jegrička Rivers, Serbia. J Environ Sci Health Part A Toxic/Hazard Subst Environ Eng 48(10):1201-1215. https:// doi.org/10.1080/10934529.2013.776848

38. Official monitoring programme (2013) Studija: Monitoring površinskih voda u AP Vojvodini u 2013. godini. Novi Sad, Prirodno-matematički fakultet, Departman za hemiju, biohemiju i zaštitu životne sredine

39. Official monitoring programme (2015) Studija: Monitoring kvaliteta životne sredine u AP Vojvodini u 2015. godini. Novi Sad, Prirodnomatematički fakultet, Departman za hemiju, biohemiju i zaštitu životne sredine

40. Dalmacija B, Prica M, Ivancev-Tumbas I, van der Kooi A, Roncevic S, Krcmar D, Bikit I, Teodorovic I (2006) Pollution of the Begej Canal sedimentmetals, radioactivity and toxicity assessment. Environ Int 32(5):606-615. https://doi.org/10.1016/j.envint.2006.01.006

41. Tunić T, Knežević V, Kerkez Đ, Tubić A, Šunjka D, Sanja L, Brkić D, Teodorović I (2015) Some arguments in favour of a Myriophyllum aquaticum growth inhibition test in a water-sediment system as an additional test in risk assessment of herbicides. Environ Toxicol Chem 34(9):21042115. https://doi.org/10.1002/etc.3034

42. Feiler U, Kirchesch I, Heininger P (2004) A new plant-based bioassay for aquatic sediments. J Soils Sediments 4(4):261-266. https://doi. org/10.1007/BF02991122

43. Stešević D, Feiler U, Sundić D, Mijović S, Erdinger L, Seiler TB, Heininger P, Hollert H (2007) Application of a new sediment contact test with Myriophyllum aquaticum and of the aquatic Lemna test to assess the sediment quality of Lake Skadar. J Soils Sediments 7(5):342-349. https://doi. org/10.1065/jss2007.08.249

44. Planojević I, Teodorović I, Bartova K, Tubić A, Jurca T, Kopf W, Machat J, Blaha L, Kovačević R (2011) Wastewater canal Vojlovica, industial complex Pancevo, Serbia-preliminary ecotoxicological assessment of contaminated sediments. J Serbian Chem Soc 76(3):459-478 http://www.doise rbia.nb.rs/Article.aspx?!D=0352-51391100036P

45. Bergtold M, Dohmen G (2011) Biomass or growth rate endpoint for algae and aquatic plants: relevance for the aquatic risk assessment of herbicides. Integrat Environ Assess Manag 7(2):237-247. https://doi. org/10.1002/ieam.136

46. Knauer K, Mohr S, Feiler U (2008) Comparing growth development of Myriophyllum spp. in laboratory and field experiments for ecotoxicological testing. Environ Sci Pollut Res Int 15:322-331. https://doi.org/10.1007/ s11356-008-0008-1

47. Hussner A, Meyer C, Busch J (2009) The influence of water level and nutrient availability on growth and root system development of Myriophyllum aquaticum. Weed Res 49:73-80. https://doi.org/10.111 1/j.1365-3180.2008.00667.x 